\title{
Gladys Fairfield de Alberto Blest Gana: La maldición del amor ${ }^{1}$
}

\section{Gladys Fairfield by Alberto Blest Gana: The Curse of Love}

\author{
EDSON FAÚNDEZ V. ${ }^{a}$ \\ MARÍA LUISA MARTÍNEZ M. ${ }^{a}$ \\ ${ }^{a}$ Universidad de Concepción. \\ Correos electrónicos: efaundez@udec.cl,marluimar@gmail.com
}

Gladys Fairfield es una novela que no ha recibido suficiente atención por parte de la crítica especializada, lo que puede explicarse, en parte, por los juicios negativos expresados por eminentes comentadores de la obra literaria de Alberto Blest Gana. La relectura de esta novela permite iluminar zonas aún oscurecidas de la escritura narrativa de Blest Gana y reflexionar, entre otros aspectos, sobre las continuidades, desplazamientos y metamorfosis que adoptan las posiciones de deseo desplegadas por sus personajes femeninos.

Palabras claves: novela chilena, realismo literario, deseo mimético, celos, mal.

Gladys Fairfield is a novel that has not been given enough attention by the specialized critics, partly as the result of the negative appraisal of distinguished commentators of Alberto Blest Gana's literary work. This novel allows to bring light to the still-in-the-dark areas of Blest Gana's narrative and to reflect on, among other aspects s the continuities, displacements, and metamorphosis adopted by the positions of desire displayed by his female characters.

Key words: Chilean novel, literary realism, mimetic desire, jealousy, curse.

\footnotetext{
${ }^{1}$ Artículo escrito dentro del marco del proyecto Fondecyt Regular No 1171498 "Sentidos, formas y figuraciones del mal en la novela chilena producida entre 1858 y 1929".
} 


\section{INTRODUCCIÓN}

Gladys Fairfield (1965) es la última novela escrita por Alberto Blest Gana y está dedicada a su esposa Carmen Bascunán Valledor, quien fallece en 1911. Los comentadores de la obra novelesca del escritor chileno han desestimado esta novela, ${ }^{2}$ señalando que se emparenta con la etapa (folletinesca) ${ }^{3}$ previa a la Aritmética en el amor y al "buen realismo" (Alone, 1955: 211); que su argumento es muy simple (Latcham, 1959; Bellini, 1988); que podría ser una continuación de la fábula desarrollada en Los trasplantados (Poblete, 1995); que más bien parece un cuento que "no vale casi nada" (Silva, 1955: 334). Los escasos análisis remiten, en general, a problemas extratextuales tales como la biografía del autor y los posibles antecedentes que orientaron la construcción del personaje Florencio Almafuente. No penetran, sin embargo, en el intricado entramado deseante de la novela, que se actualiza a partir de la visibilización de tres matrimonios acaudalados reunidos en "las poéticas orillas del lago Lemán" (Blest Gana, 1965: 134)4 en Montreux, Suecia: los estadounidenses Gladys Fairfield (antes del matrimonio Gladys Venturbridge) y Néstor Fairfield; la hispanoamericana Katy Vickery (antes del matrimonio Catalina Canos) y el estadounidense Mister Vickery; y los hispanoamericanos Rafaela Almafuente (antes del matrimonio Rafaela Canos) y Florencio Almafuente. Al igual que en la novela Los trasplantados (1902), Blest Gana opta en Gladys Fairfield por no precisar la nacionalidad de los personajes hispanoamericanos y le da continuidad a su estudio sobre sujetos vanidosos deslumbrados por lo que consideran signos de distinción europeos ${ }^{5}$, aunque este tema aparece como trasfondo de lo que se constituye en la diferencia distintiva de la breve novela de 1912: la compleja red de relaciones deseantes que ilumina las rivalidades miméticas que dominan los territorios del amor y son el epicentro del mal. Su estudio permite leer de

${ }^{2}$ Gladys Fairfield es una de las novelas de la producción literaria de Alberto Blest Gana que carga con los efectos de la opinión negativa de los críticos. Jorge Román-Lagunas en "Bibliografía anotada de y sobre Alberto Blest Gana", trabajo publicado en 1980, advierte sobre las preferencias de los críticos y la consecuente postergación de una parte importante de las novelas que componen el corpus novelesco del escritor chileno. Román-Lagunas se refiere a las novelas producidas antes de 1860, pero es factible utilizar los mismos argumentos para intentar explicar la insólita falta de interés por la última novela de Blest Gana. Laura Janina Hosiasson recoge esta conclusión del trabajo de Román-Lagunas en su artículo "Siete novelas de Blest Gana: una visión de conjunto" (2017) y asume el desafío que implica estudiar las novelas menos abordadas por la crítica especializada.

${ }^{3}$ Respecto de la presencia y significación de la literatura folletinesca en Chile, sugerimos la lectura de los trabajos de Eduardo Barraza, en particular el artículo "La tradición del folletín y de la novela popular en Chile (canon y corpus en la narrativa chilena. Siglos XIX y XX)” (2017).

${ }^{4}$ Todas las citas de Gladys Fairfield llevarán en adelante sólo número de página. Ver referencias bibliográficas.

${ }^{5}$ Katy Vickery se refiere, en una conversación con Gladys Fairfield, a "los graves defectos de la educación moderna de la familia hispanoamericana” (153). La solución al problema educacional que diseña Katy está signada por el desprestigio de lo que ella estima propiamente latino (el sentimentalismo) y la valoración positiva de la antigua severidad de la educación española y de los actuales juegos de la raza sajona. El culto al otro extranjero, que se considera superior y digno de imitación, se impone en el discurso de la joven hispanoamericana. 
un modo inédito Gladys Fairfield, novela injustamente desplazada al olvido, e intensificar la incipiente reflexión, a partir de un enfoque teórico-crítico que facilita el examen de las posiciones de deseo de los personajes femeninos, sobre los sentidos y figuraciones del mal en las ficciones realistas de Alberto Blest Gana.

\section{Gladys Fairfield}

Gladys es presentada por el narrador como una mujer bella y virtuosa, quien ha sacrificado su idealismo romántico para convertirse en esposa del Mayor Fairfield, héroe de guerra que destaca por su irreprochable conducta moral. Ella experimenta, sin embargo, una "transformación repentina de su espíritu" (134) cuando conoce a Florencio Almafuente, verdadero "triunfador de recatos femeniles" (142). La belleza del joven seductor, primero, y, después, la comunicación clandestina a partir de "furtivas miradas" (142), el descubrimiento de la fama de "hombre peligroso" (140) y la atractiva diferencia cifrada en el acento extranjero de Almafuente despiertan en Gladys las aspiraciones pasionales obliteradas por las normas sociales que impone su condición de mujer casada. El deseo pasional de Gladys transgrede el principio de fidelidad monopolístico, que establece que "los placeres sexuales [son de] un uso interno al matrimonio y conforme a sus fines" (Foucault, 2007a: 172). El placer de Gladys, que se desplaza y se derrocha (sugiriendo una economía del placer distinta) fuera del matrimonio, revela la crisis de una relación conyugal que surge y se desarrolla sin el imperio de una pasión amorosa. Desde esta perspectiva, su deseo irrumpe transgrediendo la ley del matrimonio y enseñando su falencia, ya que dicha ley no puede ser refractaria (eso pareciera proponer Blest Gana) a un "haz de relaciones que son las del afecto, del apego y de la reciprocidad" (2007a: 173), fundamental para articular la comunidad matrimonial.

Existe una diferencia radical entre los deseos de Gladys y de Almafuente. En Gladys, señala el narrador, la pasión amorosa es "espontánea y turbulenta" (141), mientras que en el "héroe de alcoba" (156) es "calculadora y precavida" (141). La concreción de las respectivas expectativas de la pareja de amantes clandestinos se diluye, porque pertenecen a mundos imaginarios distintos y despliegan diferentes posiciones de deseo. Gladys ve en Almafuente un tipo de hombre, un ideal romántico, que contrasta con la rudeza de los ímpetus violentos de "sport, de batalla y de insaciable ambición pecuniaria" (141) que ella atribuye a las figuras masculinas y que su marido claramente representa. La belleza de Florencio la cautiva y sus juramentos de amor la hacen experimentar un sentimiento nuevo, una subyugación de la voluntad y la creencia de que "el que hablaba en ese momento era un revelador" (141). Debe interpretarse con cautela, sin embargo, la declarada espontaneidad de la pasión amorosa de Gladys, pues su inclinación hacia el seductor se produce sobre la base de la mediación romántica que activa su "fantasía femenil" (136). Estamos ante un deseo artísticamente mediatizado y no ante un deseo verdaderamente pasional, en el sentido propuesto por René Girard (1985), esto es: liberado de la prisión del deseo 
mimético que ocultan las ficciones románticas y desnudan las ficciones realistas. ${ }^{6}$ No son las lecturas de textos literarios, ${ }^{7}$ que gatillan el deseo mimético de, por ejemplo, Edelmira Molina en Martín Rivas, Abelardo Manríquez en El ideal de un calavera o Matías Cortaza en El loco Estero, las que posibilitan que Gladys se figure "al apuesto mozo un descendiente de los hidalgos de Velázquez" (136) o perciba en detalles corporales "una gracia byroniana" (136) o imagine que en su existencia "la poesía de la vida debía agitar sus alas tornasoladas" (159). El deseo de Gladys surge a partir de un idealismo artístico-poético, el que, según una de las claves de la escritura de Blest Gana, puede considerarse un atributo de las mujeres. El narrador de La fascinación (1913), al referirse a la joven Adelaida, "poeta por organización, como gran parte de las mujeres" (128), establece de manera patente este rasgo que perdura hasta la última novela del escritor chileno: "Hay almas de mujer capaces de elevarse a las más sublimes alturas del idealismo artístico, pues la joven se le presentaba iluminando los más apartados horizontes de la pasión aplicada al arte con la exquisita finura de la mujer, que es esencialmente artística hasta en sus menores concepciones" (164). El idealismo artístico de Gladys, si bien parece natural, se despliega a partir de la seducción que suscita en ella la obra de Diego Velázquez, venerado sistema de representación de la realidad, que transfigura a Almafuente en "el Grande de España", un personaje extraído del pincel del artista barroco español; y de complejas relaciones que se establecen entre los personajes femeninos, reveladoras de la forma de mediación del deseo privilegiada en la novela: la mediación interna, que identificamos cuando la distancia entre el sujeto deseante y el mediador "es suficientemente reducida como para que las dos esferas penetren, más o menos profundamente, la una en la otra" (Girard, 1985: 15). Este tipo de mediación puede advertirse, por ejemplo, en la exacerbación del interés de Gladys por Florencio a partir del relato de Katy sobre las aventuras amorosas del seductor, de su rompimiento

${ }^{6}$ Las ficciones realistas, según René Girard (1985), revelan el carácter mimético del deseo, distanciándose de las ficciones románticas que ocultan a los mediadores del deseo para postular que éste es libre, espontáneo y natural. Girard plantea que el deseo mimético es triangular (sujeto, mediador y objeto) y que el deseo siempre surge sobre la base de un otro, el mediador.

${ }^{7}$ Las escenas de lectura, de la misma manera que en Los trasplantados, se supeditan a breves indicaciones reveladoras de lecturas de periódicos de París que realizan el Mayor Fairfield, Mr. Vickery y Rafaela, quien lee en el "Figaro" la noticia de un "escándalo del mundo elegante de París" (167), que sirve como espejo para advertir a Gladys y Almafuente sobre las consecuencias del adulterio. Mencionamos también las lecturas de un telegrama (Mayor Fairfield) y de las cartas escritas por el Mayor a Gladys, y por Gladys a Florencio (que es interceptada por Rafaela y genera la creativa intervención de Katy Vickery, que ya analizaremos). Las miradas que Gladys dirige a Florencio, con el objetivo de "leer en el fondo de su alma" (156), son recurrentes. El diálogo secreto de los rostros no los convierte necesariamente en rostros transparentes. Su opacidad, sin embargo, produce, como si se leyera un texto literario, que los vacíos sean llenados por las expectativas del observador. La lectura de miradas, por lo tanto, no se encuentra exenta del engaño que domina la recepción de obras literarias, que, citando a Gilbert K. Chesterton, puede generar una especie de ebriedad, una idolatría del símbolo y "una indiferencia hacia la vida". Chesterton escribe: "Los riesgos de enajenación mental que conlleva la literatura se deben no tanto al amor por los libros como a la indiferencia hacia la vida, los sentimientos y todo cuanto aparece reflejado en los libros" (2009: 14). 
con "una prima y muy amiga de Rafaela" (140) y de los celos que Gladys experimenta cuando advierte la belleza de la mujer de Almafuente. ${ }^{8}$ La turbulencia del deseo pasional de Gladys también es relativa, porque la batalla interna que libra entre su moralidad y su transgresiva inclinación amorosa transita entre la negación de la sensualidad, la renuncia a la consumación del adulterio e incluso el deseo de confesar a su marido su pasión por Florencio. Esta perturbación que la pasión introduce se resuelve con el reencauzamiento de sus deseos sobre la base de la "exigencia conciliadora del matrimonio" (161) realizada a Florencio, petición que Hernán Poblete califica de "ordenada y burguesa proposición [que deshace] las ilusiones románticas" (1995: 245). El dominio que Gladys impone sobre su pasión por Almafuente restringe su placer a la dimensión de los sueños interiores; su deseo de confesar la verdad, la de su propio placer (ya sea en la suspendida confesión al Mayor Fairfield o en la carta que dirige a Almafuente), señala que la palabra (oral o escrita) se convierte en el único territorio posible para el despliegue del placer que el entramado social textualizado en la novela le niega. Placer y palabra se anudan en lo que llamamos con Michel Foucault un ars erotica asociada a la producción de la verdad:

A menudo se dice que no hemos sido capaces de imaginar placeres nuevos. Al menos inventamos un placer diferente: placer en la verdad del placer, placer en saberla, en exponerla, en descubrirla, en fascinarse al verla, al decirla, al cautivar y capturar a los otros en ella, al confiarla secretamente, al desenmascararla con astucia; placer específico en el discurso verdadero sobre el placer (Foucault, 2007b: 89).

Gladys termina articulándose como un personaje que se desplaza entre el despliegue y el repliegue de su pasión amorosa, entre la transgresión de las normas sociales y el convencionalismo del medio al que pertenece. Almafuente comprende que la transformación espiritual sufrida por la joven estadounidense la aleja de las mujeres adúlteras que pueblan el imaginario romántico del relato que él habita y desea: "Soy de parecer que la mujer que ama no debe razonar sobre los obstáculos que le impiden caer en los brazos del hombre amado" (161). El seductor es permisivo con las intenciones propias y con las dudas entre las que se debate la joven casada; no sólo la absuelve de una falta a su compromiso matrimonial, señalándole que "ante el verdadero amor, el imperio de la conciencia en punto de fidelidad

\footnotetext{
${ }^{8}$ Rafaela posee la reputación de mujer altiva, acostumbrada a arrebatar los novios a sus amigas para luego desecharlos, a pesar de su "muy discutible belleza" (139), como señalan los pretendientes desdeńados. Al inicio de la novela, Rafaela es descrita como "una mujer, alta y delgada, [que] rescataba apenas con su esbeltez la desfavorable impresión que producía una sombra de penoso descontento, dominante en la expresión de su rostro" (135), mientras que Almafuente exhibe "todo el aire satisfecho del que tiene la seguridad de ser notablemente hermoso" (135). Gladys revierte luego esta apreciación de Rafaela a partir del deseo que experimenta por Almafuente, quien dota ahora a su mujer de un atractivo que Gladys no había advertido con anterioridad: "Aquella mujer que Florencio tenía entre los brazos llegaba a parecerle hermosa [...] Esa mujer era su rival, o más bien, pensó Gladys, yo soy la rival de ella puesto que estoy disputándole el corazón de su marido. Ella tiene un cuerpo de preciosas proporciones, lo que basta muy a menudo, según dicen, para enamorar a los hombres" (143).
} 
desaparece" (143), sino que le aconseja persistir en su empeńo. Sin embargo, Gladys no puede liberarse de la norma social, motivo por el que estima necesario el divorcio como condición para el despliegue de su pasión amorosa. El deseo que la gobierna no desaparece, sino que se desplaza hacia regiones imaginarias en las que puede fluir con una libertad mayor: la escritura. Es muy significativa, desde esta perspectiva, la breve carta de amor que le envía Gladys a Florencio:

Usted me perdona, ¿no es verdad, mi muy querido? Es preciso que me lo diga usted antes de separarnos. Su perdón me servirá de apoyo en el porvenir y siempre estaré dispuesta a cumplir a usted mi promesa de recobrar mi libertad legal para pertenecerle con honor (163).

En primer lugar, la carta, espacio privilegiado para el discurso del amor, utilizado por Blest Gana desde sus primeras novelas-folletín, expresa el carácter privado y secreto de la pasión amorosa, vulnerado por la fractura de la comunicación entre el emisor (Gladys) y el destinatario (Florencio). La captura de la carta -y, por lo tanto, del secreto del placer de Gladys- por un lector con otras expectativas (Rafaela) produce que el texto del placer clandestino se concretice de un modo distinto y se active la censura y el peso de la prohibición de la ley matrimonial. En segundo lugar, la carta de amor, como lo propone Anne Carson (2015), proyecta un mundo idealizado que no tiene correspondencia con el prosaico mundo real, a la vez que encierra una paradoja erótica, pues conecta y separa a los amantes, produciendo placer y dolor. El sujeto femenino revela mediante la escritura su vacío existencial, lo que implica la visibilización del fracaso de la promesa implícita en el contrato matrimonial. La frustración de Gladys se intensifica en la medida en que su carta no encuentra respuesta en Florencio, no sólo porque la carta nunca llega a sus manos, sino porque, además, en el caso de que Almafuente la hubiera recibido, el propósito y la promesa de una entrega carnal de la joven dentro de los límites de un matrimonio serían desestimados. El encuentro de los amantes ya había señalado diferencias fundamentales en la comprensión del romance; mientras Gladys plantea la necesidad de un divorcio para una nueva unión "con la frente alta y orgullosos de darnos una prueba de amor que no nos excluiría del trato de la gente honrada" (160), Almafuente, ajeno al sacrificio que la joven exige y frustrado en sus expectativas sensuales, señala: "Usted habla de unión y olvida, mi seductora amiga, que soy casado y católicamente casado. Nuestra religión no admite el divorcio" (160). El deseo de Gladys se presenta, consecuentemente, como un deseo solitario que habita sólo en el territorio de la escritura, un deseo a la deriva, incompatible dentro del marco del escenario social. Los amantes sólo existen en el espacio de la carta, pues, como advierte Patrizia Violi, allí "el sujeto real es inaccesible, se coloca continuamente en otro lugar sólo alcanzable en el simulacro de la escritura" (1987: 89). El placer de los amantes, agrega Violi, deviene incorpóreo y no necesita de intercambio, motivo por el que ellos se convierten en construcciones imaginarias. El placer, proscrito en el espacio del matrimonio, se desplaza hacia los territorios imaginarios de la ficción en la que Gladys emerge como una 
figura femenina que se constituye en diferencia radical a partir de la mediación romántica que la domina. ${ }^{9}$

Gladys se caracteriza, en suma, por la existencia de una posición de deseo romántico, que se desplaza hacia regiones más secretas e imaginarias en la medida en que ella acoge "el impulso de su lealtad y de su propia estimación" (160), movimiento clave para la comprensión de la disputa que se produce entre la transgresión del placer y el poder de la norma. Pero no hay en la última novela de Alberto Blest Gana un deseo verdaderamente pasional, liberado de la vanidad, de la imitación, de las prohibiciones de las sociedades normalizadoras y del egoísmo del yo, como el que permite la unión de Martín Rivas y de Leonor Encina en Martín Rivas (1862) -con las atenuaciones que impone la lectura de Jaime Concha (1972)-, de Carlos Díaz y de Deidamia en El loco Estero o las trágica relaciones de Mercedes Canalejas y Patricio Fuentealba en Los trasplantados (1904) y de Luisa Bustos y Abel Malsira en Durante la Reconquista (1897)..$^{10}$ La última novela de Blest Gana mantiene el cuestionamiento a los contratos matrimoniales y plantea que en la resistencia a la trampa de la sensualidad, clave en las novelas realistas que desnudan la mentira encubierta por las ilusiones románticas, se aprecian, por un lado, los afectos y estrategias de resistencia que signan a personajes femeninos afectados por relaciones de poder, $y$, por otro, el anacronismo de un personaje como Florencio, que puede explicarse mediante el examen de las características de los nuevos escenarios sociales retratados por el escritor chileno en Gladys Fairfield. Esto último resulta significativo, porque permite que la novela sea leída como un relato que incorpora y expulsa posiciones de deseo romántico, y como un relato dominado por personajes femeninos. La lectura de Alone (1955), que establece una filiación romántica de la novela, no penetra, por consiguiente, en la complejidad de los deseos (románticos) de los personajes femeninos de las novelas, los que son exorcizados o desplazados hacia territorios ficcionales. Desde esta perspectiva, Gladys Fairfield postula un resquebrajamiento de los principios del amor romántico que el autor descubre luego de sus lecturas de relatos realistas. ${ }^{11}$

\footnotetext{
${ }^{9}$ Leonidas Morales (2003) en Carta de amor y sujeto femenino en Chile. Siglos XIX y XX explora, a partir del diálogo con las proposiciones de Patrizia Violi ("La intimidad de la ausencia: formas de la escritura epistolar") y de René Girard, en las mediaciones que inciden en el proceso de ficcionalización del sujeto signatario de la carta. Véase el primer capítulo del libro: "Carmen Arriagada: la carta como espacio de construcción del objeto del deseo".

${ }^{10}$ En los artículos "Martín Rivas: violencia mimética y pensamiento utópico" (Estudios filológicos, 2004, no 54: 49-67), en coautoría con Fernando Ibánez y María Luisa Martínez, y "La cárcel del deseo mimético en Los trasplantados de Alberto Blest Gana” (en prensa) nos hemos referido a estas relaciones no miméticas.

${ }^{11}$ Tomemos como ejemplo, para apreciar la distancia que se establece entre la novela publicada en 1912 y aquéllas que anteceden la publicación de La aritmética en el amor, la novela-folletín Un drama en el campo, publicada en 1859 en la revista La semana. La intriga amorosa, que se desarrolla en 1834 en la provincia de Colchagua, se establece a partir del encuentro de Pablo Reina y Paulina Mendibel, personajes virtuosos y de "aristocrática elegancia" (1949: 31). El cumplimiento de su proyecto amoroso se posterga por los obstáculos que presentan Antonio Reina, quien, dominado por los celos, intenta asesinar a su hermano, y el padre de Paulina,
} 


\section{Rafaela Almafuente}

El esnobismo que domina a la gran mayoría de los personajes de Los trasplantados adquiere una nueva forma de cristalización en la novela que comentamos. Una de esas variantes del esnobismo surge con los celos crónicos que singularizan a Rafaela Almafuente, porque "ser snob en el amor es abocarse a los celos. Así pues, el amor proustiano coincide con el esnobismo y basta con darle al término una extensión ligeramente mayor de la habitual para entender en él la unidad del deseo proustiano" (Girard, 1985: 28). Blest Gana intensifica así en Gladys Fairfield el examen de los sentimientos sociales que Sthendal (pero también Proust) presenta como propiamente modernos y que fueron analizados rigurosamente por René Girard en sus reflexiones sobre la mediación interna del deseo: "En Les mémoires d'un touriste, Stendhal previene a sus lectores contra lo que denomina los sentimientos modernos, frutos de la universal vanidad: la envidia, los celos y el odio impotente" (1985: 20). La revelación que realiza Katy a Gladys respecto de la ley de imitación que dirige el comportamiento prematrimonial de Rafaela reviste, en este sentido, interés:

La ley de imitación que nos gobierna, haciéndonos imitar cuanto vemos en las otras mujeres, no perdió su imperio tratándose de Rafaela, bien que ella a su vez gozaba de la reputación de muchacha altiva y poco accesible a la galantería. Era precisamente lo contrario del joven. Rafaela cifraba su orgullo en arrebatar los novios a sus amigas y al verlos rendidos a sus pies los despreciaba (139).

Rafaela, "rival feliz de todas sus amigas" (139) -incluida su prima Katy Vickery, la última rival vencida antes del matrimonio con Florencio-, ilumina la forma de su pasión amorosa. El amor vanidoso que ella profesa -al que cree renunciar sometiéndose al imperio de la ley del matrimonio- desplaza su fascinación desde el objeto de deseo hacia la disputa frenética con rivales que se transfiguran en verdaderas mediadoras de su deseo amoroso. El matrimonio la sumerge en las dudas de los celos y la convierte en una mujer infeliz, que aspira inútilmente a saberlo todo a partir de una prolija red de vigilancia: “¡Todo! ¡Ella hubiera querido saberlo todo!; poder arrojar de sí la tormentosa duda” (155). Sus celos incurables la convierten en una intérprete delirante de signos que su viva imaginación despliega en las acechanzas a sus rivales e, incluso, en la figuración de sus deseos. Jean-Luc Marion en El fenómeno erótico se refiere al funcionamiento de los celos como defensa del honor del amor y de la veracidad del otro: "Gracias a los celos asumo el honor del amor y lo defiendo contra la mentira del amante. Pues el amante, cuando desfallece, provoca una triple

\footnotetext{
personaje que rinde culto al dinero y sueńa con un matrimonio económicamente conveniente para su hija. La novela se resuelve con la fuga de los enamorados, la frustración del padre de Paulina y el autoexilio familiar de Antonio, lo que permite advertir la filiación folletinesca del relato, pues, ocultando cualquier tipo de mediación del deseo, exacerba la idea de espontaneidad y libertad del amor, a la vez que busca afectar en el plano de los sentimientos al lector real. Las posiciones que adopta el deseo amoroso en Gladys Fairfield son de una naturaleza muy distinta y pueden explicarse a partir del influjo que el estilo realista tuvo en el novelista chileno.
} 
deshonra. Primero me deshonra mintiéndome, desmintiendo entonces nuestro juramento. Luego se deshonra regresando de su estatuto de amante, oscureciendo su sinceridad. Por último, y sobre todo, deshonra el amor" (2005: 201). Florencio, desde esta perspectiva, más que por sus atributos físicos, su elegancia o su coraje, cifrado éste en la defensa del honor en el duelo con Redline (que opera como una situación paralela y homóloga al honor del amor mancillado por la traición de Florencio, honor que los celos de Rafaela procuran defender), resalta porque permite que la acaudalada Rafaela capture los flujos de deseo que surgen de la red mimética que acompaña el arribo de sus rivales femeninos. Son las mediadoras, admiradas y odiadas al mismo tiempo, las que la conducen hacia los abismos del deseo vanidoso: territorio donde es posible advertir el triunfo y la ruina, la elevación y la caída del personaje regido por rivalidades miméticas. Así lo señala el narrador al revelarnos, en el capítulo VII, que Rafaela crece en presencia física y discursiva cuando tiene "la convicción de que la suerte de su última rival estaba entre sus manos" (167), para convertirse, otra vez, en el capítulo final de la novela, en una mujer desfalleciente y atormentada por las implacables dudas. Merece una atención especial el proyecto de venganza de Rafaela; poseída por un odio furioso, descorre los velos de la quimera romántica y enseńa la imagen real de Almafuente, silenciada aún en el relato; por eso habla con "voz destemplada y vulgar" (164), clara señal de la irrupción de la verdad realista que muestra la mentira romántica: "Se casó conmigo por mi plata y con mi plata se ha divertido a costa mía [...] Un ocioso que no sabe sino componerse y galantear a cuanta mujer se le acerca" (164). La concentración en las mediadoras, que se convierten en obstáculos a vencer, ilumina y hace más visible también la figura de Almafuente (no ocurre esto con Mr. Fairfield ni con Mr. Vickery: personajes que no cautivan la atención de las tres figuras femeninas), quien contribuye a mantener con su sola existencia esa sed irresistible de rivalizar con las mediadoras. La obsesión de Rafaela por cada movimiento de los amantes clandestinos permite que el amor retroceda y que el odio emerja como sentimiento orientador de las relaciones con el otro. Ella crea y procura destruir al otro mediante su carácter obsesivo y celoso, y luego renace para volver a vestirse con la mortaja de su interioridad atormentada. Las huellas que dejan los trayectos de su deseo desviado enseñan el secreto de la relación con Florencio, con su (antigua) mediadora Katy y con Gladys, la mediadora que emerge durante su estada en Suiza. Jean-Luc Marion propone sugerentemente: "Esta concentración en alguien, porque lo odio, no solamente lo individualiza hasta el extremo, también me hace vivir a mí [...] el odio que él me permite, con el que me privilegia, en suma, que él me $d a$, hace a veces que me despierte y me obligue a volver a ser lo que era, sin saberlo todavía ni quererlo" (2005: 203). Hemos señalado que Rafaela adquiere una envergadura distinta a partir de la irrupción de los celos y del odio. Su proyecto de venganza, asociado a su delirante repudio a los amantes, enseńa de manera patente, si seguimos a Marion, cómo los celos y el odio le permiten momentáneamente vivir y ser nuevamente quien ella efectivamente es, por lo que los dones que la ilusión idealizadora y romántica del amor ya no puede entregar parecieran surgir ahora desde los territorios del mal. Los afectos del amor desplegados por Blest Gana en Gladys Fairfield son inseparables del afecto de los celos, lo que adquiere mayor relevancia en la medida en que se 
suspende en el relato la posibilidad de un encuentro amoroso fundado en la horizontalidad $\mathrm{y}$ en la responsabilidad ante el otro.

Gilles Deleuze y Félix Guattari (2017) señalan que el afecto de los celos se constituye en una de las finalidades fundamentales del deseo amoroso textualizado en la escritura novelesca de Proust: el gran novelista francés ingresa a los laberintos interiores de la pasión amorosa, en los que las fronteras que separan los celos del amor son simplemente abolidas. Los celos son finalidad y no un accidente desgraciado del amor. Así lo sugiere también Irving Singer (2006), quien advierte, en su estudio sobre Proust, sobre la significación de la síntesis del odio y del amor; incluso llega a plantear que los celos son anteriores al estallido del amor en la escritura de Proust, la que indaga en las posiciones de deseo del celoso, incrustadas en el nacimiento y pervivencia del amor. ${ }^{12}$ Blest Gana, tan apreciado por sus novelas (estudios) que retratan las costumbres sociales del siglo XIX, reflexiona sobre los complejos rostros del amor y aborda, por única vez con real profundidad psicológica, las zonas deseantes en las que los celos se desplazan y actualizan las estrechas relaciones entre amor y odio, entre el bien y el mal. El autor se contagia con una sensibilidad de época, que tiene a Proust entre sus mayores exponentes, y otorga el protagonismo de su última novela a las figuras femeninas que trazan los recorridos del deseo; incluso titula su novela con nombre de mujer, ${ }^{13}$ para advertir sobre la indisoluble unión entre los celos y el amor, y cómo los primeros transfiguran al segundo en "una maldición de la raza humana" (164).

\section{KATY VICKERY}

Katy Vickery es un personaje clave en la novela de Blest Gana, debido a que diseña estrategias que le permiten desplazarse libremente por los ámbitos del secreto, a los que apenas pueden acceder Rafaela y Gladys. Ella conoce, antes que Rafaela, la inclinación amorosa de Gladys; penetra, acompañada por Mr. Vickery, verdadero ayudante de cada uno de sus proyectos, en el espacio masculino del duelo entre Redline y Florencio; sabe de la carta acusatoria que envía Rafaela al Mayor Fairfield, por lo que decide engatusar al cartero con ardides para recuperarla, objetivo que consigue pagando 400 francos; y elabora y ejecuta un plan para conseguir que Rafaela perdone a Florencio. Es ella quien, dentro del marco de las relaciones de poder inherentes al juego de las pasiones amorosas, se convierte en guardiana de los secretos y quien termina por afectar de manera más sensible al otro. Dos

\footnotetext{
${ }^{12}$ Ortega y Gasset, quien construye una imagen del amor siempre positiva y utópica, también reflexiona sobre la relación que se establece entre los celos y el amor: "Parejamente, el amor ama porque ve que el objeto es amable, y así resulta para el amante la actitud ineludible, la única adecuada al objeto, y no comprende que los demás no lo amen -origen de los celos, que, en cierto giro y medida, son consustanciales al amor" (1964: 67).

${ }^{13}$ Llama la atención que Gladys Fairfield sea la única novela de Blest Gana titulada con nombre de mujer, lo que evidencia, por una parte, la adhesión a la fórmula de titulación de la escritura realista del siglo XIX (por ejemplo, Madame Bovary de Flaubert y Ana Karenina de Tolstoi) y, por otra parte, revela la preocupación del novelista por las posiciones de deseo de personajes femeninos.
} 
episodios resultan muy interesantes para observar su comportamiento: su interpretación de "Plaisir d'amour" de Jean Paul Égide Martini y la historia que ella cuenta al cartero para recuperar la carta escrita por Gladys. Katy, luego de que Rafaela descubre la carta que hace evidente la traición de Florencio y comienza a planificar su venganza, canta "Plaisir d'amour" de Martini, acompañándose de la música del piano y conjurando el pasado en un intento por aplacar la furia de Rafaela a partir de la música que abre un territorio de placer para las dos primas. Los versos "penas de amor que duran toda una vida" (164) y "dichas de amor que duran sólo un instante" (165) territorializan, en efecto, el placer diferido o desplazado de las primas y sus "corazones esclavos de la maldición universal del amor" (165). El espacio ficcional y utópico de la música, ${ }^{14}$ en el que los sufrimientos y el gozo del amor se convierten en pura intensidad deseante, gatilla la reconfiguración de las personajes y enseña rítmicamente, además, la matriz intertextual de la novela que hace visible la síntesis entre la condición pasajera de las dichas del amor y la condena perpetua de las penas del corazón.

La historia que Katy le cuenta al ambicioso cartero resulta interesante por la sustitución de roles desplegada, la que complejiza el entramado de relaciones deseantes de la novela. Guillermo Araya, quien aborda en sus excelentes análisis de la obra de Blest Gana las relaciones triangulares del deseo, no se detiene en las particularidades de la última novela del escritor chileno. En su trabajo "Alberto Blest Gana" sólo indica: "En Gladys Fairfield Florencio y Gladys se aman, pero la mujer de Florencio es Rafaela" (1987: 171). No advierte la singularidad del amor de los personajes y la importancia de Katy Vickery en la red de deseos que signa la novela. Katy fabula una historia para recuperar la carta que el cartero ya ha recogido y en ese relato asume el lugar de la mujer infiel (el que ocupa Gladys en la novela); la costurera que coloca la carta acusatoria en el buzón sustituye a Rafaela; el seductor continúa siendo Florencio; y el esposo engañado, Mr. Fairfield. La ficción producida por Katy refleja su dimensión deseante, inseparable de las conexiones, reciprocidades y cortocircuitos que se producen entre Gladys y Rafaela. El dinamismo del deseo, como puede apreciarse, caracteriza a las mujeres del relato, lo que se evidencia a partir de la sustitución de roles. No así a los grávidos personajes masculinos, que, reiteramos, actúan más bien como ayudantes en el despliegue del deseo de las tres jóvenes esposas. De este modo comienza a aclararse el lugar que Katy detenta en el entramado novelesco. Sus hábiles estrategias son las de un personaje que también se encuentra cautivado por la rivalidad mimética. Su fábula, otra mentira romántica, le permite capturar el lugar de la mediadora doble en la que se ha convertido Gladys. Esta propuesta de lectura adquiere mayor validez si se considera que Katy termina apropiándose también del lugar que le corresponde a Rafaela, quien desfalleciente, aunque sabe del "viejo encono de la rivalidad adormecida" (164) e interpela a su prima diciéndole "tú te quedaste enamorada de él, a

\footnotetext{
${ }^{14}$ Ernst Bloch destaca la relación entre música y utopía: "Existe el terreno totalmente utópico de la música que, conforme a la propiedad del sonido que no está localizado en ninguna parte, nadie sabe dónde acontece [...] Un núcleo utópico, al menos como en la utopía social, reside en la música” (2017: 47-48).
} 
pesar de la traición que te jugó, y hasta después de casarte con tu yanqui era él a quien querías" (164), olvida que Katy sigue siendo una rival terrible y cree, ingenuamente, que la prima le profesa un afecto sincero.

El secreto del deseo de Katy, asesina simbólica de sus rivales que la novela nos revela a través de sutiles indicios, nada tiene que ver con la acogida fraternal del otro, sugerida por la imagen que de ella construye Rafaela, luego de dejarse arrastrar hacia los territorios de la nostalgia y del placer que activan la palabra y la música de "Plaisir d'amour" de Martini. Tiene que ver más bien con la vanidad herida y con el odio producido por la pérdida de Florencio, sentimientos que ella vela y oculta. Su intenso rencor la condena a seguir unida a Rafaela, su rival mimético, y a Florencio, el objeto deseante, y constituye el verdadero motivo por el que se empeńa en mantener la unidad del matrimonio Almafuente y expulsar a Gladys Fairfield del sistema deseante en el que ella ejerce el dominio. Así puede continuar en el juego de la pasión amorosa, del que no puede sustraerse. El diálogo entre Katy y Florencio, con el que se cierra la novela, es esclarecedor en este sentido:

- ¡Oh! ¿La carta?; no vas a suponer que yo la habré guardado para entregártela. Si te perdono tus locuras, no voy a llevar mi debilidad a favorecer tus amores.

- Mi único verdadero amor es el que te tuve a ti -dijo el joven, estrechando a Katy entre sus brazos.

$[\ldots]$

- ¿Hasta el año entrante?

- ¡Quién sabe, mejor sería hasta nunca! -exclamó Katy, suspirando, llenos de lágrimas los ojos (173).

Katy, luego de referir la aventura de la carta (que es la aventura de la escritura sin destinación: de la pasión que invoca y exorciza la presencia del otro, de la soledad del sujeto deseante y de la autofiguración del yo en el espesor del lenguaje), perdona a Florencio, cuando debería ser Rafaela quien le conceda el perdón a su marido por traicionar el honor del amor. Katy se desplaza de este modo hacia el lugar de la esposa celosa, de la prima que le arrebató el amor de Almafuente; la vence, la expulsa, sin que Rafaela siquiera se entere, haciéndose evidente, entre otros aspectos, la reversibilidad de las rivalidades miméticas y el triunfo asociado a la posesión del secreto. La complejidad de las posiciones de deseo de la novela se hace notoria sólo considerando estos rasgos distintivos. La victoria del odio oculto de Katy tiene un costo, que marca su diferencia respecto de la esposa celosa. Nos referimos a la perdida de la carnalidad: "La más perfecta individuación del odio tiene pues un precio: la disminución de mi carne, e incluso su desaparición. Odio, pero en el estado de cadáver" (Marion 2005: 205). La joven prescinde de la erótica de los cuerpos, pues se ha convertido en una habitante de sus territorios ficcionales (la música y la fabulación de historias), portadores de placer. La respuesta de Katy a la proposición de Florencio al final de la novela, la exclamación iquién sabe, mejor sería hasta nunca!, señala que ella prefiere el sacrificio de la pasión amorosa y el desplazamiento del placer hacia mundos imaginarios 
más que la actualización de un sueńo romántico ya perdido e imposible de reencontrar en la desencantada realidad del presente. ${ }^{15}$ Katy, en una lectura superficial, asume el papel de la heroína romántica; aparenta ser la comprensiva y discreta confidente de sus dos secretas rivales, protege y contribuye a la estabilidad del matrimonio de Florencio con su prima -una unión en riesgo por el afán de conquista y los devaneos amorosos de Almafuente-, aconseja prudentemente a Rafaela sobre la imperiosa necesidad de perdonar la traición de su marido y ayuda a Katy en la recuperación de la carta que la incrimina y que, en el caso de llegar a manos del Mayor Fairfield, significaría un escándalo y eventualmente la muerte del seductor a manos del marido burlado. Sus actos deben ser leídos, sin embargo, desde otra perspectiva: la del poder perverso que le permite superar a sus mediadoras, expulsarlas subrepticiamente de los afanes románticos de Florencio y gozar del placer solitario que le otorga esta curiosa revancha. Su relativo triunfo no consiste en la obtención del objeto deseado, porque Almafuente no dejará de ser el seductor que es y que ella conoce; tampoco debe considerarse inocentemente el tardío reconocimiento de Florencio de que Katy ha sido su único verdadero amor, declaración que ella puede comprender con escepticismo y con mucha justicia en atención a los hechos. La conquista de Katy Vickery reside en la obtención de los secretos que los otros personajes ocultan y que ella devela. El detalle de las lágrimas en la escena que cierra la novela no se relaciona con la nostalgia por el novio robado o por la revitalización de una posición de deseo romántico, sino que debe pensarse asociado a la imposibilidad de fuga de esta mujer atrapada en la red de las relaciones miméticas que dibuja la fisonomía de la maldición del amor retratada en las postreras páginas de Alberto Blest Gana.

\section{Obras Citadas}

Alone. 1955. Don Alberto Blest Gana. Santiago de Chile: Editorial Nascimento.

Araya, Guillermo. 1987. "Alberto Blest Gana", en Historia de la Literatura Hispanoamericana. Tomo II. Del neoclasicismo al modernismo. Luis Ińigo Madrigal (Coordinador). Madrid: Cátedra.

Barraza, Eduardo. 2017. "La tradición del folletín y de la novela popular en Chile (Canon y corpus en la narrativa chilena siglos XIX y XX)". Revista chilena de literatura, 96: 115-140.

Bellini, Giuseppe. 1988. "Alberto Blest Gana 'historiador de Chile'” Rassegna Iberistica. Estratto, 31: 3-17.

Blest Gana, Alberto. 1965. El loco estero y Gladys Fairfield (Prólogo de Hernán Díaz Arrieta "Alone"). Santiago de Chile: Editorial Zig-Zag.

\footnotetext{
${ }^{15}$ Esta sublimación es equivalente al imaginario romántico que Gladys despliega en la carta que dirige a Florencio o en la representación de Almafuente como una imagen extraída de los cuadros de Velázquez, y que Rafaela habita a través de la ensońación que la música de Martini evoca.
} 
. 1949. Un drama en el campo. Santiago de Chile: Editorial Zig-Zag. . 1913. La fascinación. París: Librería de la Vda. De Ch. Bouret.

Bloch, Ernst. 2017. ¿Despedida de la utopía? Madrid: A. Machado Libros.

Carson, Anne. 2015. Eros. El dulce-amargo. Buenos Aires: Fiordo.

Chesterton, Gilbert K. 2009. Lectura y locura y otros ensayos imprescindibles. Salamanca: Ediciones Espuela de Plata.

Concha, Jaime. 1972. "Martín Rivas o la formación del burgués". Revista chilena de literatura, 5 y 6: 9-36.

Deleuze, Gilles; Guattari Félix. 2017. ¿Qué es la filosofía? Barcelona: Editorial Anagrama.

Faúndez, Edson; Ibáñez Fernando; Martínez, María Luisa. 2014. "Martín Rivas: violencia mimética y pensamiento utópico”. Estudios Filológicos, 54: 49-67.

Faúndez, Edson. 2019. "La cárcel del deseo mimético en Los trasplantados de Alberto Blest Gana”, Revista de literatura y lingüistica (en prensa).

Foucault, Michel. 2007a. Historia de la sexualidad. 3-La inquietud de sí. México: Siglo Veintiuno Editores. . 2007b. Historia de la sexualidad. 1-La voluntad de saber. México: Siglo Veintiuno Editores.

Girard, René. 1985. Mentira romántica y verdad novelesca. Barcelona: Editorial Anagrama.

Román-Lagunas, Jorge. 1980. "Bibliografía anotada de y sobre Alberto Blest Gana”. Revista Iberoamericana, Vol. XLVI, 112-113: 605-647.

Hosiasson, Laura. 2017. "Siete novelas de Blest Gana: Una visión de conjunto". Revista Chilena de Literatura, 96: 235-258.

Marion, Jean-Luc. 2005. El fenómeno erótico, Buenos Aires: El Cuenco de Plata.

Morales, Leonidas. 2003. Carta de amor y sujeto femenino en Chile. Santiago de Chile: Editorial Cuarto Propio.

Ortega y Gasset, José. 1964. Estudios sobre el amor. Madrid: Revista de Occidente.

Poblete, Hernán. 1995. Alberto Blest Gana y su obra. Santiago de Chile: Pehuén Editores.

Silva Castro, Raúl. 1955. Alberto Blest Gana 1830-1920 (segunda edición refundida). Santiago de Chile: Editorial Zig-Zag.

Singer, Irving. 2006. La naturaleza del amor: el mundo moderno. México D.F.: Siglo Veintiuno Editores.

Violi, Patrizia. 1987. "La intimidad de la ausencia: formas de la escritura epistolar". Revista de Occidente, no 68: 87-96. 